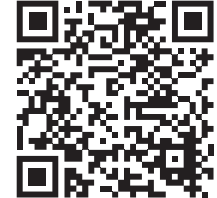

* Comisión de Bioética del Estado de Campeche, Médico Cirujano,

Especialidad en Patología Clínica.

Correspondencia: EGS, eduardogarsol@gmail. com

Conflicto de intereses: Ninguno.

Citar como: García-Solís E. Servicio social en medicina ¿debe continuar? Rev CONAMED. 2021; 26(2): 98-100. https://dx.doi. org/10.35366/100353

Financiamiento: Ninguno.

Recibido: 22/02/2021.

Aceptado: 16/06/2021.

\section{Servicio social en medicina ¿debe continuar?}

\author{
Social service in medicine must continue? \\ Eduardo García-Solís*
}

\section{RESUMEN}

Una pregunta que se hace la sociedad, principalmente la médica, a raíz de los acontecimientos recientes durante los que ha perdido la vida de la forma más injusta una pasante de medicina, no obstante haber alertado de las amenazas recibidas sin que hubiese una respuesta satisfactoria. Razón por la que es necesario revisar la permanencia del servicio social en medicina. Existe una Norma Oficial Mexicana, NOM-009-SSA3-2013, que establece los criterios para la utilización de los establecimientos para la atención médica como campos clínicos para la prestación del servicio social de medicina. El médico pasante en servicio social se debe sentir seguro, y no en indefensión cuando no tiene el apoyo que en teoría debería recibir de las autoridades sanitarias y de educación. Por ningún motivo el médico pasante debe estar solo en una unidad médica sin la supervisión y asesoría de médicos titulados, que aseguren su integridad física y psicológica. Sólo así el servicio social realizado por el pasante en medicina tiene su razón de ser. El médico pasante en servicio social es un alumno en formación.

Palabras clave: Servicio, social, medicina, continúa.

\section{ABSTRACT}

A question that society asks itself, mainly the medical, as a result of recent events in which a medical student her life in the most unjust way. However, she had warned of the threats she had had without there being a satisfactory answer. It is necessary to review the permanence of social service in medicine. There is an Official Mexican Standard, NOM-009-SSA3-2013. That establishes the criteria for the use of establishments for medical care as clinical fields for the provision of social service of medicine. The medical student in social service must feel safe, and not feel defenseless. When they do not receive the support that in theory he should receive from the health and education authorities that feeling of insecurity gets worse. Under no circumstances should the medical student be alone in a medical unit, without the supervision and advice of qualified doctors, ensuring their physical and psychological safety. Only then, the social service performed by the medical student has its reason for being. The medical student in social service is a student in training.

Keywords: Social, service, medicine, keep going. 


\section{INTRODUCCIÓN}

Una pregunta que se hace la sociedad, principalmente la médica, a raíz de los acontecimientos recientes durante los cuales ha perdido la vida de la forma más injusta una pasante de medicina, no obstante haber alertado de las amenazas recibidas sin que hubiese una respuesta satisfactoria. Para referir al servicio social es necesario recordar al Dr. Gustavo Baz Prada que organiza la primera brigada médica para ofrecer servicios de salud a la comunidad de Atlixco, Puebla. Siendo Rector de la Universidad Nacional Autónoma de México (UNAM) instaura el servicio social con carácter de obligatorio para todos los pasantes de la UNAM. En el año 1936 la primera generación iría a lugares donde no hubiera médicos, con un maletín de diversos productos biológicosy una remuneración de 90 pesos?

Y unas palabras de aliento del Dr. Baz que en aquellos tiempos decía «tienen ustedes ya seis años de estudio, lo normal sería que dentro de unos meses reciban el título. En lugar de eso, les vengo a pedir que se presten patrióticamente a uno de los experimentos más singulares que habrá de registrar la historia de la medicina: cada uno de ustedes irá a un lugar donde no haya médico y pasará allí seis meses ejerciendo las funciones de inspector sanitario y de facultativo. Las medicinas que necesiten las mandaremos nosotros, no cobrarán ustedes por sus servicios, el Gobierno les asignará un sueldo mensual de 90 pesos; a la mayoría les tocará en suerte ejercer su ministerio entre personas primitivas y rudísimas, hijos incultos de la sierra, del bosque y del páramo que no tienen la más leve noticia de lo que es el moderno arte de curar.

El deber de ustedes será introducir aunque sea los rudimentos de higiene y recoger hechos, datos, estadísticas sobre el modo de vida de cada lugar, cada uno de ustedes remitirá un informe mensual y al cabo de seis meses escribirá una tesis con la historia del lugar, el tipo de población, el clima, el régimen alimenticio usual, los medios económicos de vida, estado sanitario y las causas de la morbilidad...»

Palabras llenas de emoción que en su época estuvieron justificadas, hace 85 años, cuando se aplicaban los conocimientos y habilidades aprendidas en las aulas y hospitales, reforzando su ánimo y templanza al atender y decidir qué tratamiento es el mejor para el paciente que acudía con confianza en búsqueda de la salud. Una oportunidad de regresar a quien más lo necesita, un tributo a la ciudadanía que ha contribuido a la educación médica. Éste es en esencia el objetivo del servicio social.

En la actualidad es necesario revisar la permanencia del servicio social en medicina. Existe una Norma Oficial Mexicana, NOM-009-SSA3-2013, que establece los criterios para la utilización de los establecimientos para la atención médica como campos clínicos para la prestación del servicio social de medicina y estomatología, ${ }^{3}$ y la Secretaría de Salud, como instancia rectora, tiene la atribución para establecer las bases con el fin de implementar y conducir la política nacional que eleve la calidad de los servicios y, de manera simultánea, apoyar la formación de recursos humanos para la salud que den respuesta efectiva a las necesidades de la población en materia.

Entre sus apartados se señala:

- 6.13 Atender de inmediato, en coordinación con las instituciones de educación superior y la participación que corresponda a las autoridades competentes de la localidad, las denuncias o quejas, tanto del pasante como de la comunidad, por actos $u$ omisiones que afecten la prestación del servicio social o pongan en riesgo la integridad física del pasante en el campo clínico, a fin de implementar las medidas oportunas para su solución.

- 8.3 Denunciar ante las autoridades competentes de la localidad e informar a las instituciones de salud y de educación superior cuando se presente algún incidente que afecte la prestación del servicio social o se considere que pone en riesgo su integridad física, para que las mismas procedan a atenderlo en el ámbito de su competencia.

- 9.2 Área exclusiva para habitación, descanso, alimentación y aseo de los pasantes en condiciones de privacidad y seguridad en el campo clínico o en su defecto, un lugar en la localidad que cumpla con lo referido, sin costo para el pasante cuando deba permanecer disponible después del horario de atención que corresponde al campo clínico.

La Norma Oficial Mexicana del servicio social en medicina es de carácter obligatorio; no obstante, 
en ocasiones no se cumple, tan es así que en $2013^{4}$ se señalaba una importante inequidad desde la creación del servicio social en medicina, y es que los pasantes en su gran mayoría son asignados a unidades rurales donde atienden a las poblaciones más pobres y marginadas del país. En su condición de estudiantes (no titulados), sin licencia, deben llevar a cabo funciones formalmente autorizadas sólo a médicos que han recibido dicha licencia. Los estudiantes pasan entre seis meses y un año en la unidad asignada y después pueden recibir su título. A lo anterior se suma el hecho de que en los últimos años las condiciones de violencia social en algunas regiones del país han convertido la práctica del servicio social en una actividad sumamente riesgosa.

No hay que olvidar que el médico pasante en servicio social es un alumno, por lo que es indispensable que se formen buenos médicos con programas educativos supervisados, con evaluaciones precisas de la enseñanza. Por tal motivo es necesario el compromiso de las instituciones de salud y educativas en que el servicio social sea una herramienta mediante la cual el alumno sea un médico con conocimientos, habilidades y humanismo que ayude al enfermo. ${ }^{5}$

El médico pasante en servicio social se debe sentir seguro, y no en indefensión cuando no tiene el apoyo que en teoría debería recibir de las autoridades sanitarias y de educación. Esto sucede cuando un pasante es designado para acudir a una unidad médica y está solo con su enfermera, situación que se daba años atrás con un gran dilema cuando al médico pasante se le presentaba una urgencia médica como una tromboembolia pulmonar. ¿Qué hacer? con el consecuente estrés para el pasante y el riesgo para el enfermo.
Aunque actualmente se procura que el médico pasante no esté solo, en ocasiones no es así. De ahí la importancia de que se revise el beneficio del servicio social en medicina. El caso que se presentó en Chiapas es sólo una muestra de otros tantos casos. Por ningún motivo el médico pasante debe estar solo en una unidad médica sin la supervisión y asesoría de médicos titulados, que aseguren su integridad física y psicológica. Sólo así el servicio social realizado por el pasante en medicina tiene su razón de ser. El médico pasante en servicio social es un alumno en formación.

\section{AGRADECIMIENTOS}

A la Comisión de Bioética del estado de Campeche.

\section{REFERENCIAS}

1. Mazón RJ, Delgado FA, Sánchez RG. https/: facmed.unam. $\mathrm{mx} / \mathrm{deptos} / \mathrm{ss} / w p$-content/uploads/2018/10/El-ServicioSocial-Medico.pdf

2. El Servicio Social en Medicina. Disponible en: www.gob.mx/ salud/articulos/el servicio-social-en.medicina-en-mexico

3. Norma Oficial Mexicana NOM-009-SSA3-2013, Educación en Salud. Criterios para la utilización de los establecimientos para la atención médica como campos clínicos para la prestación del servicio social de medicina y estomatología. Disponible en: https://www.dof.gob.mx/nota_detalle.php? codigo=5354092\&fecha=28/07/2014\#: :text=NORMA\%20 Oficial\%20Mexicana\%20NOM\%2D009,social\%20de\%20 medicina\%20y\%20estomatolog\%C3\%ADa

4. Nigenda G. Servicio social en medicina en México. Una reforma urgente y posible. Salud Publica Mex. 2013; 55 (5): 519-527.

5. Rivero O. Consideraciones sobre problemas actuales de la enseñanza de la medicina en México. Disponible en: http:// publicaciones.anuies.mx/pdfs/revista/Revista22_STATES.pdf

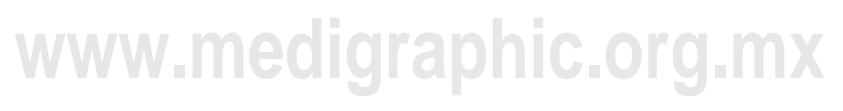

